\title{
Filling of extraction sockets of feline maxillary canine teeth with autogenous bone or bioactive glass ${ }^{1}$
}

\author{
Adelina Maria da Silva', Rafael Dias Astolphi" ${ }^{\mathrm{II}}$, Sílvia Helena Venturoli Perri" ${ }^{\mathrm{II}}$, Marion Burkhardt de Koivisto ${ }^{\mathrm{IV}}$ \\ ${ }^{I} \mathrm{PhD}$, Assistant Professor, Department of Clinics, Surgery and Animal Reproduction, Sao Paulo State University (UNESP), Araçatuba-SP, Brazil. \\ Conception, design, intellectual and scientific content of the study; acquisition and interpretation of data; surgical procedures; radiographic, macroscopic \\ and histopathological examinations; manuscript writing.

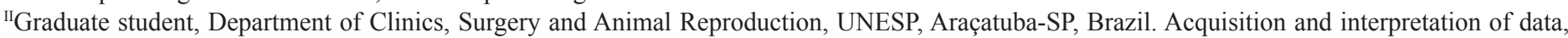 \\ surgical procedures, radiographic and macroscopic examinations. \\ IIIPhD, Assistant Professor, Department of Biosciences, Production and Animal Health, UNESP, Araçatuba-SP, Brazil. Statistical analysis. \\ ${ }^{\mathrm{IV}}$ Associate Professor, Department of Clinics, Surgery and Animal Reproduction, UNESP, Araçatuba-SP, Brazil. Acquisition and interpretation of data, \\ histometric examinations.
}

\begin{abstract}
PURPOSE: To evaluate bone healing in the extraction socket of the feline maxillary canine tooth after grafting.

METHODS: Eighteen adult cats were submitted to unilateral extraction of maxillary canine tooth and divided into three groups. In group $1(n=6)$, control, the extraction socket was left empty. In group $2(n=6)$, the extraction socket was filled with autogenous cancellous bone from the iliac crest and in group $3(n=6)$, with bioactive glass particulate material. Cats were euthanized at four weeks postoperative.

RESULTS: The radiographic examinations performed four weeks after surgery showed that in all groups the healing process converged to a radiopacity similar to that observed in the surrounding bones. Histological examination showed formation of woven bone within the extraction socket. The percentage of newly formed bone within the extraction socket, measured by the histometry, showed no statistically significant difference among the values of the three groups (Kruskal-Wallis'test p $>0.05$ ) (group 1: 63.96 \pm 5.85 , group 2: $66.84 \pm 11.67$, group 3: $59.28 \pm 15.50)$.
\end{abstract}

CONCLUSION: The bone regeneration observed in the extraction sockets filled with autogenous cancellous bone or bioactive glass was similar to that observed in the control sites, given an observation period of four weeks after extraction of the maxillary canine tooth. Key words: Surgery, Oral. Bone Transplantation. Tooth Extraction. Tooth Socket. Cats. 


\section{Introduction}

The use of a variety of materials to fill extraction sockets has been studied in order to accelerate bone regeneration, maintain alveolar ridge and reinforce the resistance of the maxilla or mandible ${ }^{1-8}$. Some of the more common indications for extraction of teeth in cats include crown fracture with pulp exposure, periodontal disease, feline odontoclastic resorptive lesions and feline chronic gingivostomatitis ${ }^{9-13}$.

Autogenous cancellous bone is still regarded as the best material, because of its osteogenic, osteoinductive and osteoconductive properties. But one of its disadvantage is the need of a second surgical procedure at the donor site ${ }^{14,15}$.

The bioactive glass is a bioactive ceramic that has the ability to bond to bone tissue. Bioactive glass particles are composed of salts of calcium, sodium, phosphorus and silica. When implanted in living tissue, the granules undergo a surface reaction that results in the formation of a calcium phosphate layer that is substantially equivalent to the hydroxyapatite found in bone mineral. This layer provides scaffold for bone growth. The bioactive glass particles also form a cohesive mass when contacting the blood, thereby exhibiting hemostatic properties ${ }^{1,16}$.

The objective of the present study was to evaluate bone formation resulting from the placement of autogenous cancellous bone or bioactive glass into fresh extraction sockets in cats.

\section{Methods}

This study was approved by the Ethics Committee for Animal Research of UNESP, Araçatuba-SP, Brazil.

Eighteen healthy young adult (aging between 12 and 36 months) mixed breed cats (weighing $3.2 \pm 0.3 \mathrm{~kg}$ ) were utilized. Nine spayed females and nine neutered males were used and evenly distributed among 3 groups. Unilateral extraction of mandibular canine tooth was performed at random in either the right or left side. In group 1, control, the extraction socket was left empty. In group 2, the extraction socket was filled with autogenous cancelous bone from the iliac crest and in group 3, with bioactive glass particulate material (Consil Dental Bioglass ${ }^{\circledR}$, Nutramax Laboratories, Inc. by NovaBone Products, LLC, Alachua, FL, USA). Cats were euthanized at four weeks postoperative

\section{Surgical procedure}

Food was withheld for 12 hours prior to anesthesia. The cats were premedicated with atropine $(0.05 \mathrm{mg} / \mathrm{kg} \mathrm{SC})$, xylazine
(2 mg/kg SC) and ketamine (15 mg/kg SC). Thiopental (5mg/kg IV) was administered to allow endotracheal intubation. Inhalation anesthesia was maintained with halothane and oxygen. Fentanyl $(0.0125 \mathrm{mg} / \mathrm{kg} \mathrm{IM})$ was administered after anesthesia induction. Lactated Ringer's solution (10 mL/kg IV) was administered throughout anesthesia. Ketoprofen ( $2 \mathrm{mg} / \mathrm{kg}, \mathrm{SC})$ and enrofloxacin $(5 \mathrm{mg} / \mathrm{kg}, \mathrm{SC}$ ) were administered preoperatively and for three days postoperatively.

Cats of group 2 were positioned in lateral recumbency and the iliac crest region was clipped, prepared, and draped under sterile technique. Using an $\mathrm{n}^{\circ} 10$ Bard-Parker blade, a $4 \mathrm{~cm}$ incision was made over the iliac crest. The subcutaneous tissue, gluteal fat and thoracolumbar fascia were incised to expose the crest and the wing of the ilium. A block of cortico-cancellous graft was harvested from the iliac wing with an osteotome and mallet. Small particles of cancellous bone (1 to $3 \mathrm{~mm}$ diameter) were obtained and stored in saline at room temperature. Subcutaneous layer was closed with 3-0 polyglicolic acid. Skin closure was with 4-0 nylon. Skin sutures were removed after seven days.

Thereafter the cats of the three groups were prepared for oral surgery with povidone-iodine. Local anesthesia of the infraorbital nerve was done with mepivacain $(7 \mathrm{mg} / \mathrm{kg})$ and epinephrine. A buccal mucoperiosteal flap was raised with periosteal elevator to expose the extraction socket of the maxillary canine tooth. A burr on a slow-speed handpiece under irrigation with sterile saline was used to perform buccal alveolectomy (Figure 1). Root elevator and extraction forceps were used to complete the extraction. On completed extraction, the remaining alveolus was debrided with a curet and irrigated with sterile saline solution. In group 1, control, the extraction socket was left empty. In group 2, the extraction socket was filled with autogenous cancellous bone from the iliac crest and in group 3, with bioactive glass particulate material (Figure 2). The flap was sutured with 4-0 polyglyconate in a simple, interrupted pattern.

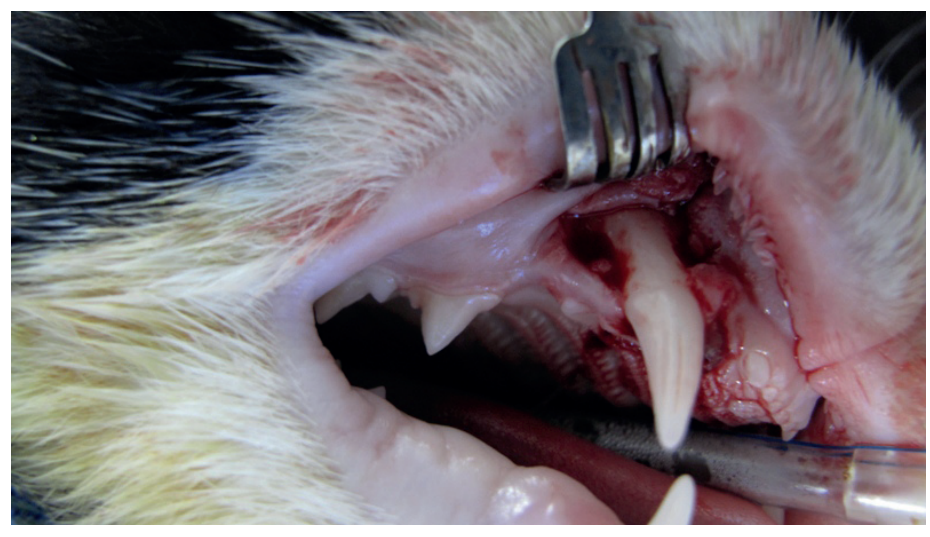

FIGURE 1 - Buccal alveolectomy performed before maxillary canine tooth extraction. 


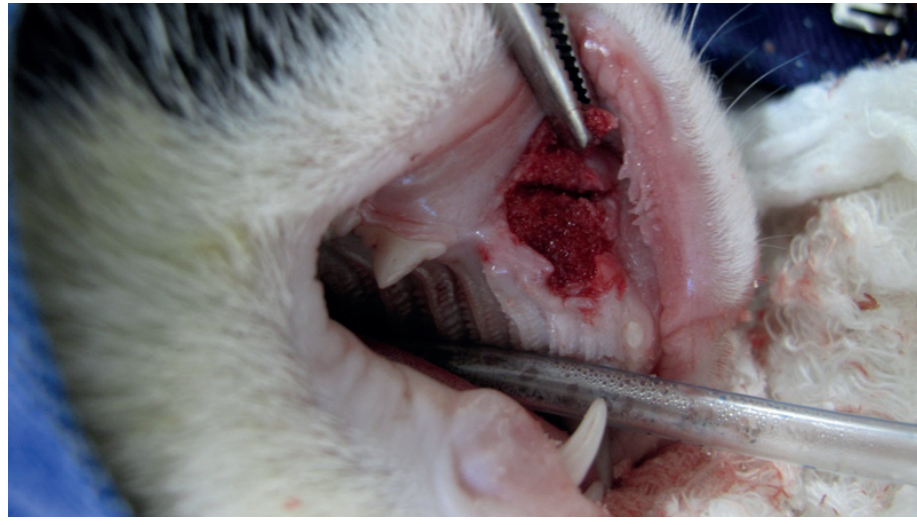

FIGURE 2 - Extraction socket of maxillary canine tooth filled with bioactive glass.

\section{Postoperative observations and radiographs}

Oral alimentation was reinitiated 24 hours after surgery with canned food. This soft food was offered during five days. After this period, the animals were fed with commercial dry feline diet. Intraoral radiographs were performed immediately after surgery and at the end of the study, i.e., after four weeks postoperative.

\section{Macroscopic analysis, histolopathology and histometry}

The cats were euthanized at four weeks postoperative by intravenous thiopental overdosage. Block sections of the maxilla that contained the extraction wounds were fixed in $10 \%$ formalin. The undecalcified specimens were dehydrated in ethanol, clarified in xylol and embedded in glycol methacrylate. Thin sections were made transversely and stained with Masson-Goldner, toluidine blue and hematoxylin-eosin for microscopic evaluation. For the histometric analysis, the images of sections were acquires using a digital camera (Olympus DP71) coupled to a microscope (Olympus BX61). The percentage of newly formed bone within the extraction socket was measured using the Image Pro Plus 6.1 software.

\section{Statistical analysis}

Non-parametric tests were utilized for the data analysis, taking into consideration the nature of the variables. McNemar'test was performed to compare data between immediate postoperative radiographs and radiographs taken at four weeks postoperative. Fisher's exact test was used to compare the results of the immediate postoperative radiographs between groups. KruskalWallis' test was used to compare histometric data among the three groups. SAS software was used to conduct the analyses (Statistical
Analysis System, release 9.2. SAS Institute Inc., Cary, NC, USA, 2008). Significance was set at $\mathrm{p} \square 0.05$.

\section{Results}

No case of crown and/or root fracture occurred during dental extraction. There were no clinical complications. No case of oronasal fistula or root remnants was observed. During the experimental period the cats showed normal activity and mastication. Good healing of the extraction wound was observed in 14 cats (Figure 3 ). In four animals (one cat from group 1, one cat from group 2 and two cats from group 3) the mucoperiosteal flap was not properly done and because of that, complete epithelization was not present four weeks after surgery. Oral mucosal sutures of 4-0 polyglyconate were not removed, and usually disappeared. But in seven cats, some sutures were still present four weeks after surgery. Cats from group 2, in which autogenous bone graft was harvested from the iliac wing, showed normal deambulation after surgery. The surgical wounds in the iliac crest region also healed satisfactorily.

Immediate postoperative intraoral radiographs of control animals showed a radiolucent area at the extraction wound (Figure 4). In group 2 (extraction sockets filled with particulate autogenous cancelous bone), three animals showed radiolucency at the extraction wound. The other three cats of group 2 showed radiopacity, and it was possible to see the bone particles (Figure 5). Strong radiopacity was observed in extraction sockets filled with bioactive glass (Figure 6). The radiographic examinations performed four weeks after surgery showed that in all groups the healing process converged to a radiopacity similar to that observed in the surrounding bones (Figure 7). The result of McNemar'test was significant in control group since the extraction wound changed from radiolucent to radiopaque in intraoral radiographs taken at 4 weeks postoperative (Table 1). The result of Fisher's exact test was significant when the immediate postoperative radiographs of control group were compared with those of group 3 (bioactive glass) (Table 2). 


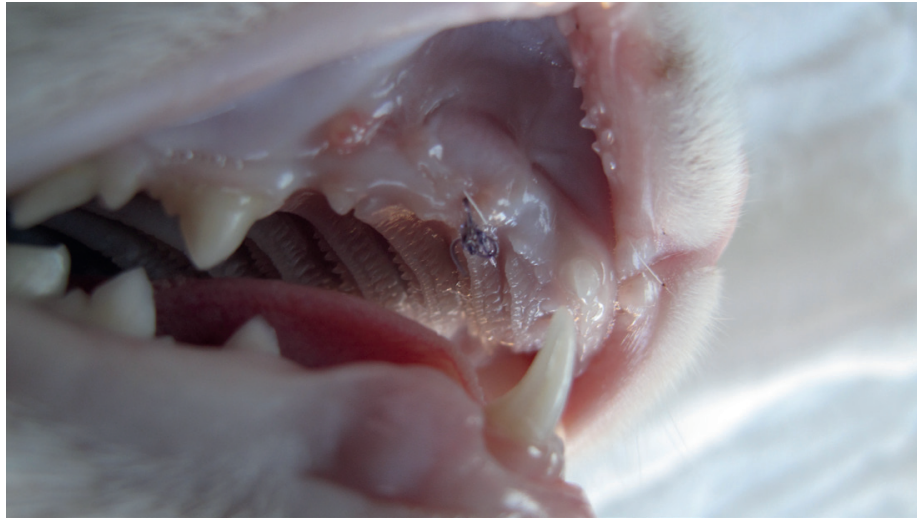

FIGURE 3 - Good healing of the extraction wound four weeks after surgery. Sutures were still present. Cat 16 from group 3 (bioactive glass)

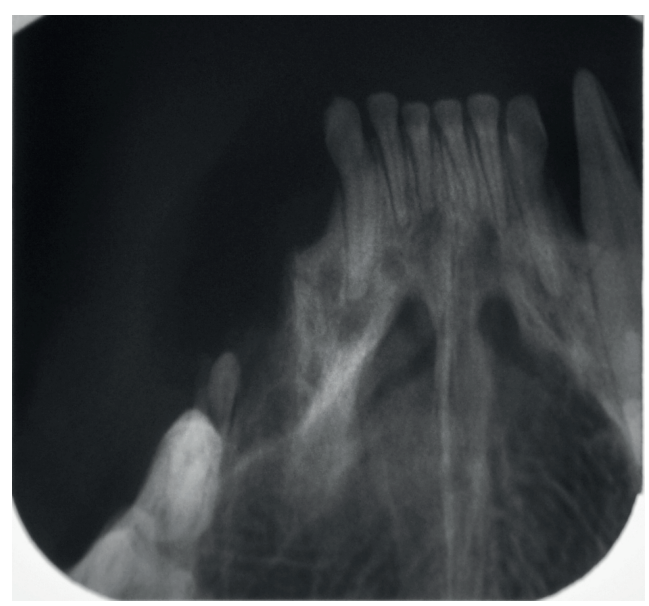

FIGURE 4 - Immediate postoperative intraoral radiograph shows a radiolucent area at the extraction wound. Cat 2 from Group 1 (control).

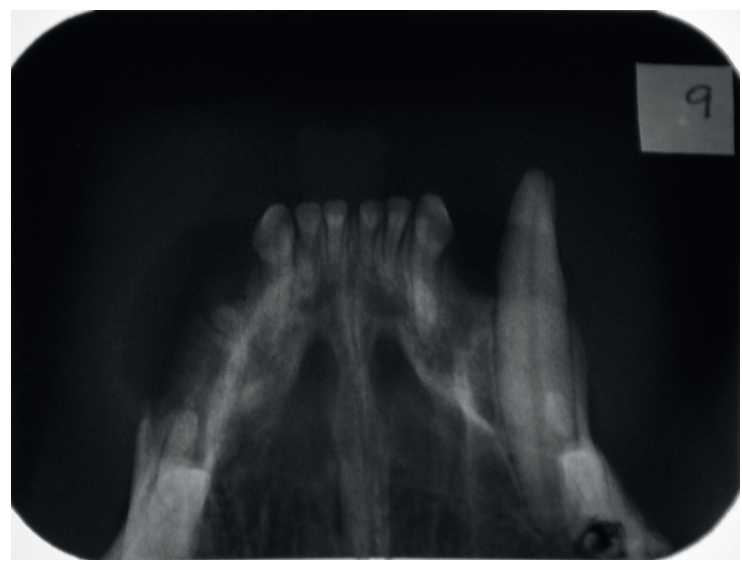

FIGURE 5 - Immediate postoperative intraoral radiograph shows bone particles at the extraction wound. Cat 9 from Group 2 (autogenous cancellous bone)

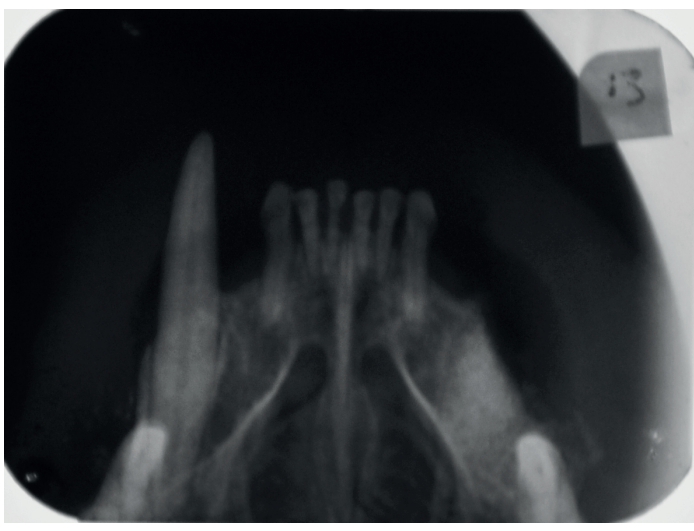

FIGURE 6 - Immediate postoperative intraoral radiograph shows strong radiopacity at the extraction wound. Cat 13 from Group 3 (bioactive glass).

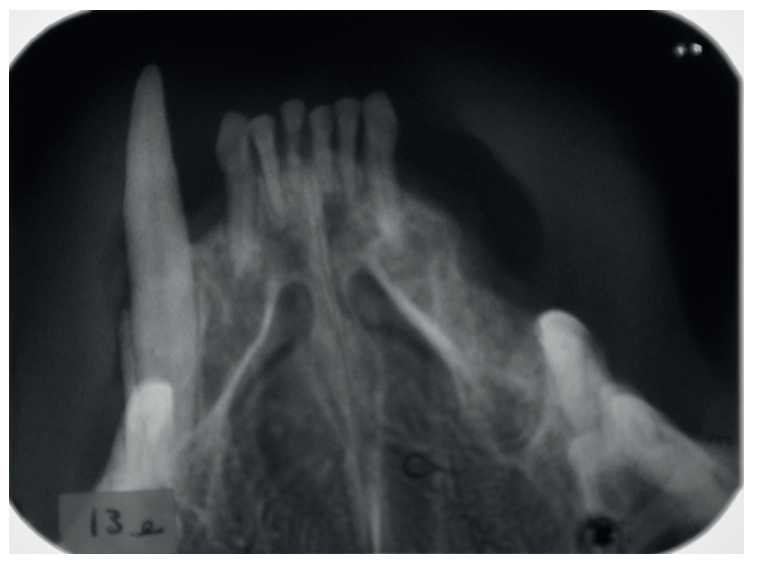

FIGURE 7 - Intraoral radiograph taken four weeks after surgery shows radiopacity at the extraction wound. Cat 13 from Group 3 (bioactive glass).

TABLE 1 - Presence or absence of radiopacity at extraction wound in the radiographs performed in the immediate postoperative and four weeks after surgery. Cats of group 1 (control).

\begin{tabular}{cccc}
\hline $\begin{array}{c}\text { Immediate } \\
\text { postoperative } \\
\text { radiographs }\end{array}$ & Absence & $\begin{array}{c}\text { Radiographs } \\
\text { taken at 4 weeks } \\
\text { postoperative }\end{array}$ & \\
\hline Presence & Total \\
Absence & - & 6 & 6 \\
Presence & - & - & 0 \\
Total & - & - & 6 \\
\hline
\end{tabular}

McNemmar'test $\quad \mathrm{P}=0.0412 *$ 
TABLE 2 - Presence or absence of radiopacity at extraction wound in the radiographs performed in the immediate postoperative from cats of group 1 (control) and group 3 (bioactive glass).

\begin{tabular}{ccccccc}
\hline Group & \multicolumn{2}{c}{ Presence } & \multicolumn{2}{c}{ Absence } & \multicolumn{2}{c}{ Total } \\
\hline & $\mathrm{n}$ & $\%$ & $\mathrm{n}$ & $\%$ & $\mathrm{n}$ & $\%$ \\
Control & - & - & 6 & 50.0 & 6 & 50.0 \\
$\begin{array}{c}\text { Bioactive } \\
\text { glass }\end{array}$ & 6 & 50.0 & - & - & 6 & 50.0 \\
Total & 6 & 50.0 & 6 & 50.0 & 12 & 100 \\
\hline
\end{tabular}

Fisher's exact test $\quad \mathrm{P}=0.0022 *$

Histological examination showed formation of woven bone within the extraction socket (Figures 8, 9 and 10). Areas of connective tissue were seen among bone trabeculae, indicating that the regeneration of extraction socket occurred by intramembranous ossification. The histologic sections showed bioactive glass particles only in the lamina propria of the gingival mucosa (Figure 11). Presumably the bioactive glass granules within the extraction sockets were disintegrated or incorporated into newly formed bone.

The percentage of newly formed bone within the extraction socket was measured by the histometry. There was no statistically significant differences among the values of the three groups (Kruskal-Wallis'test $\mathrm{p}>0.05$; group 1: $63.96 \pm 5.85$, group 2: $66.84 \pm 11.67$, group 3: $59.28 \pm 15.50$; Table 3 ).

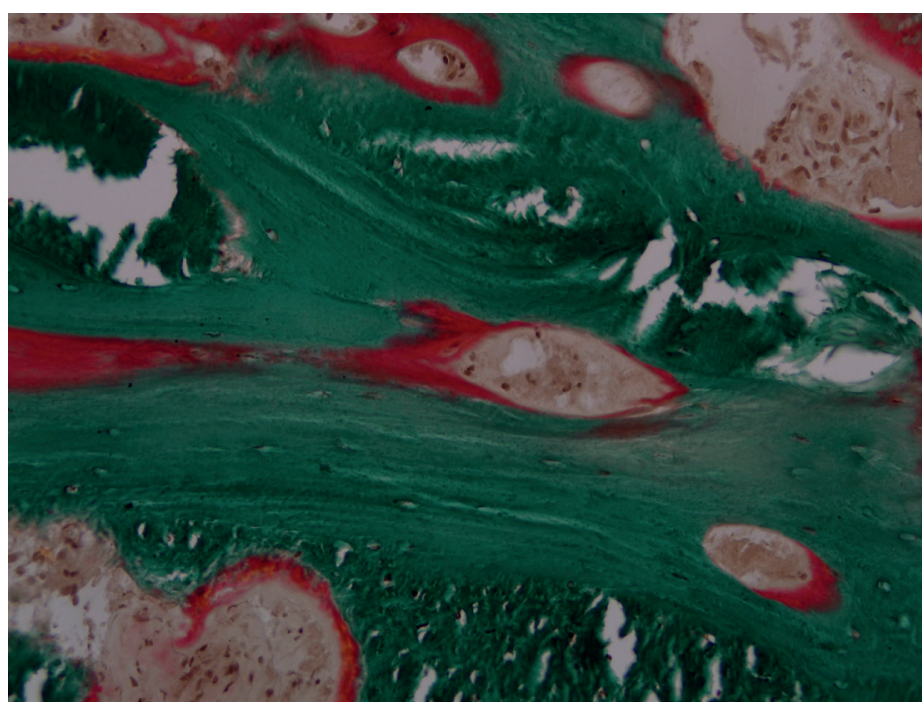

FIGURE 8 - Histologic section of extraction socket after four weeks shows woven bone formation. Mineralised bone: green. Osteoid: orange. Cat 11 of Group 2 (autogenous cancellous bone) specimen (MassonGoldener - x200).

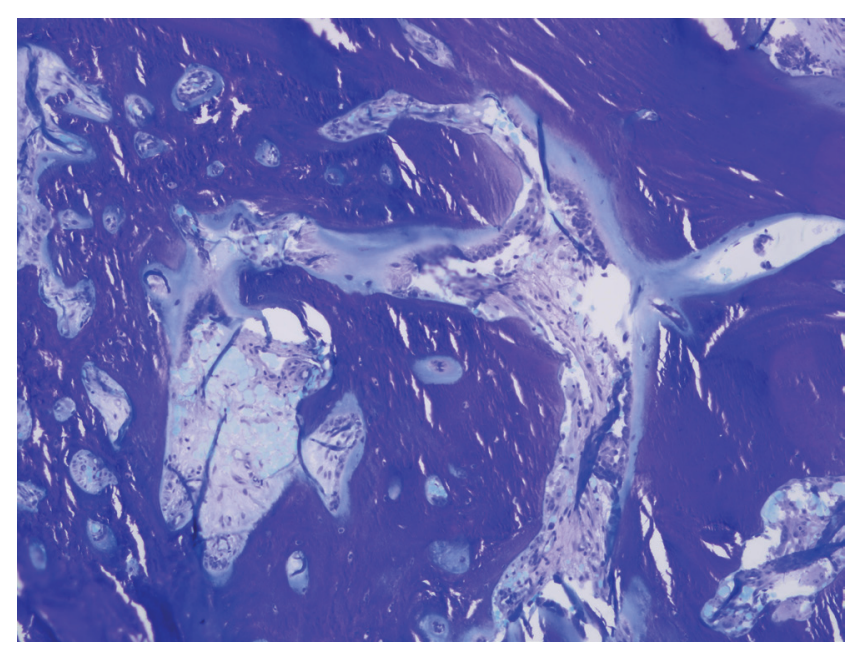

FIGURE 9 - Histologic section of extraction socket after four weeks shows woven bone formation. Cat 12 of Group 2 (autogenous cancellous bone) specimen (Toluidine blue $-\mathrm{x} 100$ ).

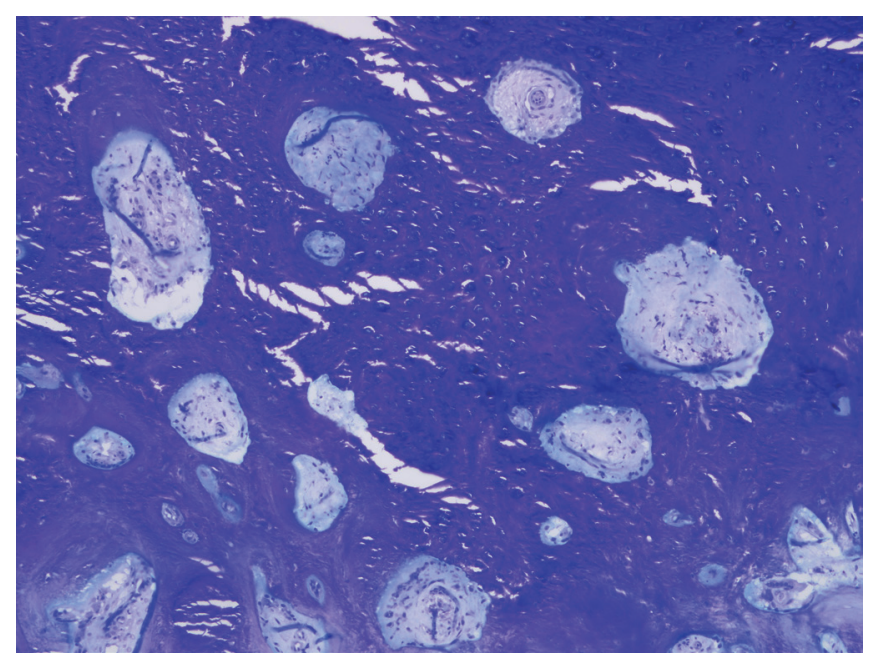

FIGURE 10 - Histologic section of extraction socket after four weeks shows woven bone formation. Cat 12 of Group 2 (bioactive glass) specimen (Toluidine blue $-\mathrm{x} 100$ ).

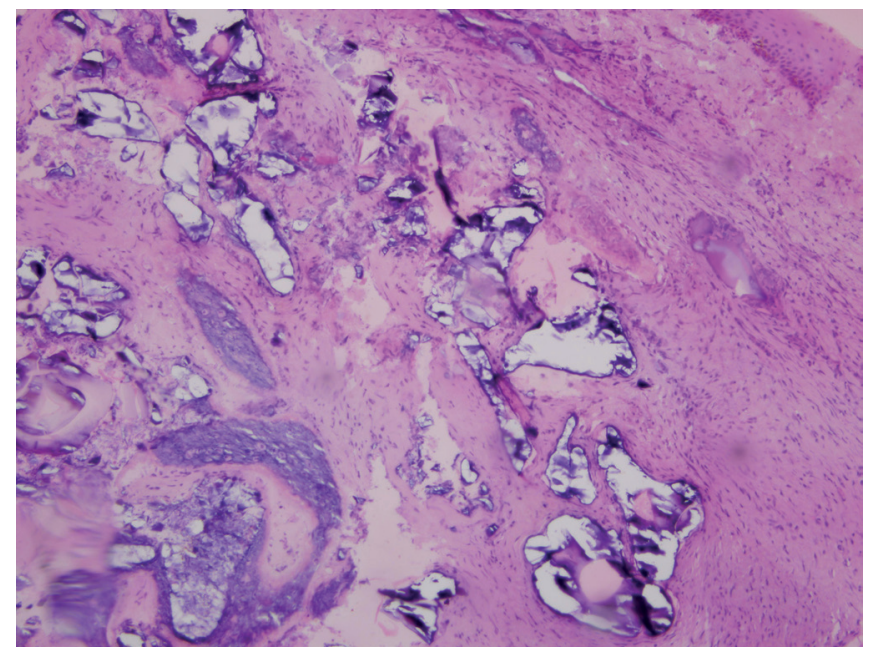

FIGURE 11 - Histologic section of extraction socket after four weeks shows bioactive glass particles in the lamina propria of the gingival mucosa. Cat 17 of Group 3 specimen. (HE - x100). 
TABLE 3 - Bone fill percentage within the extraction socket four weeks after extraction of maxillary canine tooth.

\begin{tabular}{cccc}
\hline Statistic & $\begin{array}{c}\text { group 1 } \\
\text { control }\end{array}$ & $\begin{array}{c}\text { group 2 } \\
\text { cancellous } \\
\text { bone graft }\end{array}$ & $\begin{array}{c}\text { group 3 } \\
\text { bioactive glass }\end{array}$ \\
\hline & 71.65 & 86.45 & 83.66 \\
& 67.69 & 74.05 & 63.88 \\
& 65.71 & 64.46 & 59.17 \\
& 63.95 & 62.45 & 58.97 \\
& 53.36 & 59.75 & 54.46 \\
Mean & 55.37 & 53.85 & 35.56 \\
Standard & 63.96 & 66.84 & 59.28 \\
deviation & 5.85 & 11.67 & 15.50 \\
Median & 64.83 & 63.46 & 59.07 \\
\hline
\end{tabular}

Kruskal-Wallis' test $\quad \mathrm{P}=0.3998$

\section{Discussion}

The local anesthesia of the infraorbital nerve reduced inhalant anesthetic requirement and decreased pain after surgery. Postoperative pain was also controlled with the use of nonsteroidal anti-inflammatory drugs and soft food as recommended by others studies ${ }^{3,13}$.

In the present study, no case of oronasal fistula occurred. The oronasal fistula is a possible complication after maxillary canine tooth extraction in dogs and cats. It results from avulsion of a part of the alveolar wall during extraction, creating a communication with the ipsilateral nasal cavity. Therefore, the maxillary canine tooth extraction requires some care because its root lies within millimeters of the nasal cavity's lateral wall ${ }^{13}$.

As autogenous bone stored in saline solution at room temperature for up to two hours preserve its quality according to Laursen et $a l .{ }^{17}$, harvesting of bone graft was performed before tooth extraction in order to facilitate surgical procedures.

We used small particles of 1 to $3 \mathrm{~mm}$ of cancellous bone to fill the extraction sockets in group 2. Better bone regeneration was observed in defects filled with small autogenous bone particles than in those filled with large particles ${ }^{18}$.

The intraoral radiographs provided good visualization of the extraction wound due to minimal overlapping of bones. Intraoral radiology provided better results than the extraoral radiographic technique which was used in another experiment in cats ${ }^{8}$. But probably, the best images of extraction wounds are obtained with microcomputed tomography scan, as demonstrated by Kumarswamy et $\mathrm{al}$. $^{7}$.

Bone loss resulting from partial alveolectomy and absence of canine tooth was observed as an area of radiolucency in the immediate postoperative intraoral radiographs of all six cats of group control and three cats of group 2 (autogenous cancellous bone). The bone particles were visible on radiographs of the other three cats of group 2 and these extraction wounds showed radiopacity. Strong radiopacity was observed in extraction sockets filled with bioactive glass (cats from group 3). This radiopacity became homogenous at four weeks of postoperative presumably because of disintegration of the bioactive glass particles and bone neoformation. The radiographic examinations performed four weeks after surgery showed that in all groups the healing process converged to a radiopacity similar to that observed in the surrounding bones.

The extraction sockets were filled with trabeculae of cancellous bone four weeks after surgery. The result of histological examination of this study is in agreement with those obtained in experiments performed on dogs and cats with an observation period of some weeks ${ }^{1-8}$.

The histometric data of the present study showed that there was no statistically significant difference among groups, i.e., the percentage of trabecular bone tissue in extraction sockets filled with cancellous bone $(66.84 \pm 11.67)$ or bioactive glass $(59.28 \pm$ 15.50) was similar to that observed in sockets left empty $(63.96 \pm$ 5.85), four weeks after extraction of the maxillary canine tooth.

Mean values somewhat lower, around 50\%, were observed in the histometric examinations of another experiment performed on cats, with an observation period of six weeks, in which the extraction sockets of mandibular canine teeth were filled with autogenous cancellous bone or cortical bone chips ${ }^{8}$.

The experimental study in dogs of Gauthier et $a .^{2}$ demonstrated that after three months of tooth extraction the mean rate of newly formed bone in extraction sockets filled with calcium phosphate was lower to that observed in control sites ( $45 \%$ versus $64 \%)$.

The histometric data of the experiment performed on dogs by Suba et $a l .{ }^{4}$ demonstrated that platelet-rich plasma promoted bone regeneration in its early stages (six weeks) when combined with tricalcium phosphate for the filling of extraction sockets, since the percentage of bone area was lower in the control group than in the test group $(30.8 \pm 18.8 \%$ versus $45.9 \pm 20.6 \%)$. Twelve weeks after filling, the test group still showed a slight advantage over the control group in relation to bone regeneration (52.5\% versus $49.4 \%$ ). But 24 weeks after surgery, the percentage of newly formed bone was almost equal in both groups $(62.9 \%$ in 
the test group and $61.9 \%$ in the control group).

In the canine study of De Kok et $a .^{5}$ the measured bone formation after 49 days in the extraction sockets filled with hydroxyapatite/tricalcium phosphate cylinders loaded with mesenchymal stem cells was similar to that observed in the control group (34\% versus $35 \%)$. A lower value was observed in the extraction sockets filled only with the synthetic material (25\%).

In the experimental study of Araújo and Lindhe ${ }^{6}$ the extraction sockets of dogs filled with anorganic bovine bone showed less mineralized bone in comparison with sockets that had been filled with chips of autologous bone harvested from the mandible ( $43.5 \%$ versus $57.2 \%)$. The histometric data were obtained 3 months after dental extraction.

The preclinical pilot study of Kumarswamy et al. ${ }^{7}$ evaluated four materials in the filling of extraction sockets of dogs: xenograft particulate bone and a collagen sponge plug (control), bone putty containing lidocaine, bone putty mixed with xenograft and xenograft sandwiched between bone putty. The radiographic analysis performed with a microcomputed tomography scan six weeks after surgery demonstrated comparable bone healing among groups, since the mean ratio of bone volume to total volume of extraction socket ranged from $48 \%$ to $55 \%$.

The extraction sockets filled with bioactive glass in the present study did not show a better bone regeneration than that observed in the control group or in the group of autogenous cancellous bone. Nevertheless, this synthetic osteoconductive material did not impaired bone neoformation.

\section{Conclusion}

The bone regeneration observed in the extraction sockets filled with autogenous cancellous bone or bioactive glass was similar to that observed in the control sites, given an observation period of four weeks after extraction of the maxillary canine tooth.

\section{References}

1. DeForge DH. Evaluation of Bioglass/PerioGlas (Consil) synthetic bone graft particulate in the dog and cat. J Vet Dent. 1997;14:141-5.

2. Gauthier O, Boix D, Grimandi G, Aguado E, Bouler JM, Weiss P, Dacul G. A new injectable calcium phosphate biomaterial for immediate bone filling of extraction socket: a preliminary study in dogs. J Periodont. 1999;70:375-83.

3. Indovina Jr A, Block MS. Comparison of 3 bone subsitutes in canine extraction sites. J Oral Maxillofac Surg. 2002;60:53-8.

4. Suba Z, Takacs D, Gyulai-Gaal S, Kovacs K. Facilitation of betatricalcium phosphate-induced alveolar bone regeneration by plateletrich plasma in beagle dogs: a histologic and histomorphometric study. Int J Oral Maxillofac Implants. 2004;19:832-8.

5. De Kok IJ, Drapeau SJ, Young R, Cooper, LF. Evaluation of mesenchymal stem cells following implantation in alveolar sockets: a canine safety study. Int J Oral Maxillofac Implants. 2005;20:5118 .

6. Araújo MG, Lindhe J. Socket grafting with the use of autologous bone: an experimental study in the dog. Clin Oral Implants Res. 2011;22:9-13.

7. Kumarswamy A, Moretti A, Paquette D, Padilla R, Everett E, Nares $\mathrm{S}$. In vivo assessment of osseous wound healing using a novel bone putty containing lidocaine in the surgical management of tooth extractions. Int J Dent. 2012; 2012:894815.

8. Silva AM, Souza WM, Souza NTM, Koivisto MB, Barnabé PA, Poló TS. Filling of extraction sockets with autogenous bone in cats. Acta Cir Bras. 2012;27:82-7.

9. Reiter AM, Mendoza KA. Feline odontoclastic resorptive lesions an unsolved enigma in veterinary dentistry. Vet Clin North Am Small Anim Pract. 2002;32:791-837.

10. Harvey C. Management of periodontal disease: understanding the options. Vet Clin North Am Small Anim Pract. 2005;35:819-36.

11. Niemiec BA. Fundamentals of endodontics. Vet Clin North Am Small Anim Pract. 2005;35:837-68.

12. Lyon KF. Gingivostomatitis. Vet Clin North Am Small Anim Pract. 2005;35:891-911.

13. Niemiec BA. Extraction techniques. Top Companion Anim Med. 2008;23:97-105

14. Betz RR. Limitations of autograft and allograft: new synthetic solutions. Orthopedics. 2002;25:561-70.

15. Vaccaro AR. The role of the osteoconductive scaffold in synthetic bone graft. Orthopedics. 2002;25:571-8.

16. Schepers EJG, Ducheyne P. Bioactive glass particles of narrow size range for the treatment of oral bone defects: a 1-24 month experiment with several materials and particle sizes and sizes ranges. J Oral Rehabil. 1997;24:171-81.

17. Laursen M, Christensen FB, Bünger C, Lind M. Optimal handling of fresh cancellous bone graft. Acta Orthop Scand. 2003;74:490-6.

18. Pallesen L, Schou S, Aaboe M, Hjørting-Hansen E, Nattestad A, Melsen F. Influence of particle size of autogenous bone grafts on the early stages of bone regeneration: a histologic and stereologic study in rabbit calvarium. Int J Oral Maxillofac Implants. 2002;17:498506

\section{Correspondence:}

Adelina Maria da Silva

Departamento de Clínica, Cirurgia e Reprodução Animal

Faculdade de Medicina Veterinária, Universidade Estadual Paulista (UNESP)

Rua Clóvis Pestana, 793

16050-680 Araçatuba - SP Brasil

Tel.: (55 18)3636-1404

adelinasilva@fmva.unesp.br

adelinasilva@uol.com.br

Received: Aug 14, 2013

Review: Oct 10, 2013

Accepted: Nov 12, 2013

Conflict of interest: none

Financial source: Sao Paulo Research Foundation (FAPESP) and FUNDUNESP

${ }^{1}$ Research performed at Division of Veterinary Surgical Technique, Department of Clinics, Surgery and Animal Reproduction, Sao Paulo State University (UNESP), Araçatuba-SP, Brazil. 